Brit. J. industr. Med., 1958, 15, 283.

\title{
THE ESTIMATION OF GASEOUS ACID IN DOMESTIC PREMISES*
}

\author{
BY \\ J. J. PHAIR, R. J. SHEPHARD, G. C. R. CAREY, and M. L. THOMSON \\ From the Department of Preventive Medicine and Industrial Health, University of Cincinnati College of Medicine, \\ Cinciunati, Ohio
}

(RECEIVED FOR PUBLICATION SEPTEMBER 24, 1957)

While it is generally recognized that in most episodes of high atmospheric pollution it is difficult to incriminate any one circumstance, chemical or physical, as the responsible factor, there is also a measure of agreement that during such episodes the concentration of gaseous acids (particularly sulphur dioxide) reaches a higher level than normal; in combination with other adverse factors, such as a high relative humidity, an increased particulate loading, and a low external temperature, the change in gaseous acid concentration may be sufficient to cause disturbances of pulmonary function with serious consequences to patients having a small respiratory reserve.

Previous studies of sulphur dioxide concentrations (for instance Singh, 1939) have demonstrated quite wide variations between sampling stations in an industrial city; there may also be a significant gradient between the internal and external atmosphere of a building, particularly if the windows are closed (Setterstrom and Zimmerman, 1938; Wilson, 1954). A recent survey of the 1952 London fog episode (Ministry of Health, 1954) emphasized that during periods of intense pollution many of the disabled patients retired to their beds and remained there, and in the evaluation of the reactions of such patients to increased atmospheric contamination, it would therefore seem desirable to measure the concentration of gaseous acids and other variables within the micro-environment of the home.

The great variety of methods for estimating both $\mathrm{SO}_{2}$ and $\mathrm{SO}_{3}$ have been critically reviewed by Lombardo (1953). Many, while well suited to the analysis of stack gas, lack the sensitivity necessary to detect the concentrations normally present in the general atmosphere. The conductivity method, introduced originally by Saillard and Bregmann

- This research programme was supported in part by a research grant from the National Institute of Health, Public Health Service.
(1917) and now commonly attributed to Thomas and Abersold (1929), does possess the desired sensitivity, and under carefully controlled conditions an accuracy of $1 \%$ can be attained (Thomas, 1932). Further, the relative ease of the final analysis makes the conductivity method particularly attractive for field survey work such as our own, where approaching 200 separate analyses have to be made by a semi-skilled worker in the course of an afternoon. The main disadvantages of the Thomas autometer in such a study are its size and expense; it has also been found difficult to maintain the requisite constancy of temperature, liquid and gas flow under field conditions (Giever, 1952). An alternative to continuous analysis is some form of sequence sampler. The Wilson sequence sampler has proved reasonably satisfactory for outside sampling stations, but this apparatus is too bulky and too noisy for use in the home. Accordingly, to meet the objectives of our 1956 air hygiene survey (Carey, Phair, Shephard, Thomson, and Turner, to be published), it was decided to develop a small sequence sampler that would operate in the home for periods of up to three days with a minimum of servicing. This paper discusses some of the problems encountered in the construction of this apparatus and reports some observations on the relationship between domestic and community levels of gaseous acid contaminants of the atmosphere.

\section{The Apparatus}

Two models will be described. The first has seen successful use in the 1956 air hygiene survey in the City of Cincinnati (Carey et al.), while the second, now being developed, is even smaller and overcomes some of the technical problems inherent in the original design.

Model 1.-The apparatus is enclosed in a stained and varnished wooden cabinet measuring no more than 16 in. square and $14 \mathrm{in}$. high. Ventilation of the cabinet is obtained by a series of 1 in. circular ports on the front 
face of the cabinet and a small electric exhaust fan mounted over a larger port on the rear wall of the cabinet. To minimize conduction of sound, the cabinet is lined throughout by a $\frac{3}{4}$ in. layer of "C9 acousti-celotex" (Celotex Corp.).

A general view of the working parts is given in Fig. 1. The bubbler unit consists of 12 "opticlear" glass vials (Harshaw Scientific Company) standing in a removable hardboard rack. Each vial has a $15 \mathrm{ml}$. calibration mark engraved on the side and before use is filled to this level with a standard peroxide absorbent solution $(9 \mathrm{ml}$. of $30 \% \mathrm{H}_{2} \mathrm{O}_{2}$ and $0.93 \mathrm{ml}$. of normal $\mathrm{H}_{2} \mathrm{SO}_{4}$ in 19 litres of distilled water, adjusted to an initial specific resistance of approximately $50,000 \mathrm{ohms}$ ). The vials are closed with plastic stoppers, since it was found in initial experiments that several days' contact between the stock absorbent solution and a rubber bung was capable of producing a significant alteration in electrical conductivity. The plastic stopper is pierced by two tubes; one of $3 \mathrm{~mm}$. internal diameter placed laterally is quite short, while the other, a central $1 \mathrm{~mm}$. capillary tube, extends to within 2 to $3 \mathrm{~mm}$. of the base of the vial (Fig. 2). The joints between glass and plastic are made gas tight by use of a plastic sealing compound ("glyptal", General Electric Company) applied under vacuum. The larger bore tube is connected by polyethylene tubing and a plastic quickdisconnect joint (Pioneer Plastics, Inc., Dayton, Ohio) to one of 12 solenoid valves mounted on an adjacent metal frame.

The solenoid valves (Asco valves, No. 82624) are each open for six hours in any one three-day cycle. They are controlled by an electrically driven cam (G.E.C. "tele- chron" three-day motor) bearing on 12 micro-switches (Fig. 2). The valves open in turn to a brass manifold of 1 in. internal diameter which leads to a quiet 1/70 h.p. diaphragm pump ("dyna" pump, Model 2, 115 volts). The initial output of the pump is $41 . / \mathrm{min}$., but it is reduced to approximately $1 \mathrm{l} / \mathrm{min}$., by means of a

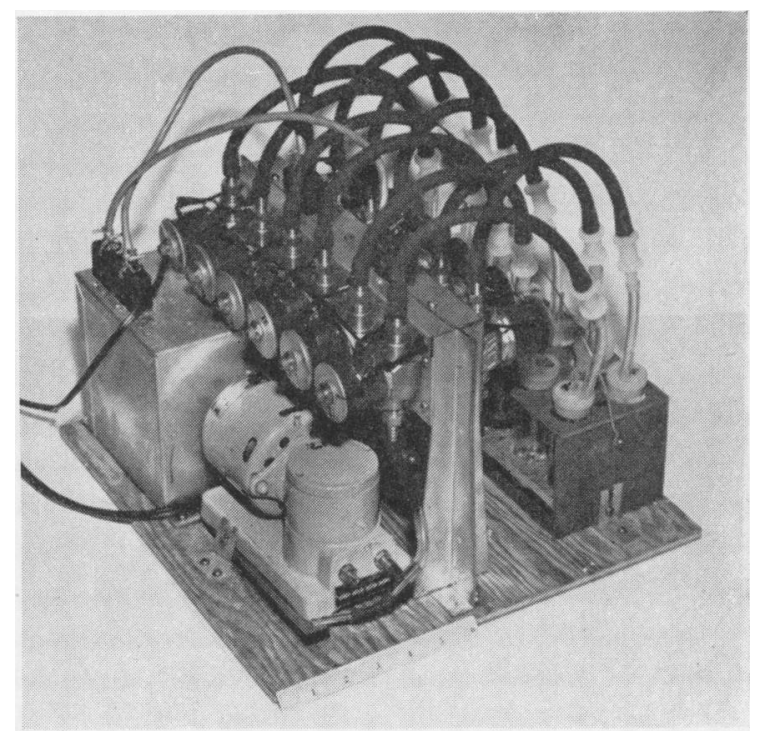

Fig. 1.-General view of sequence sampler (Model 1).

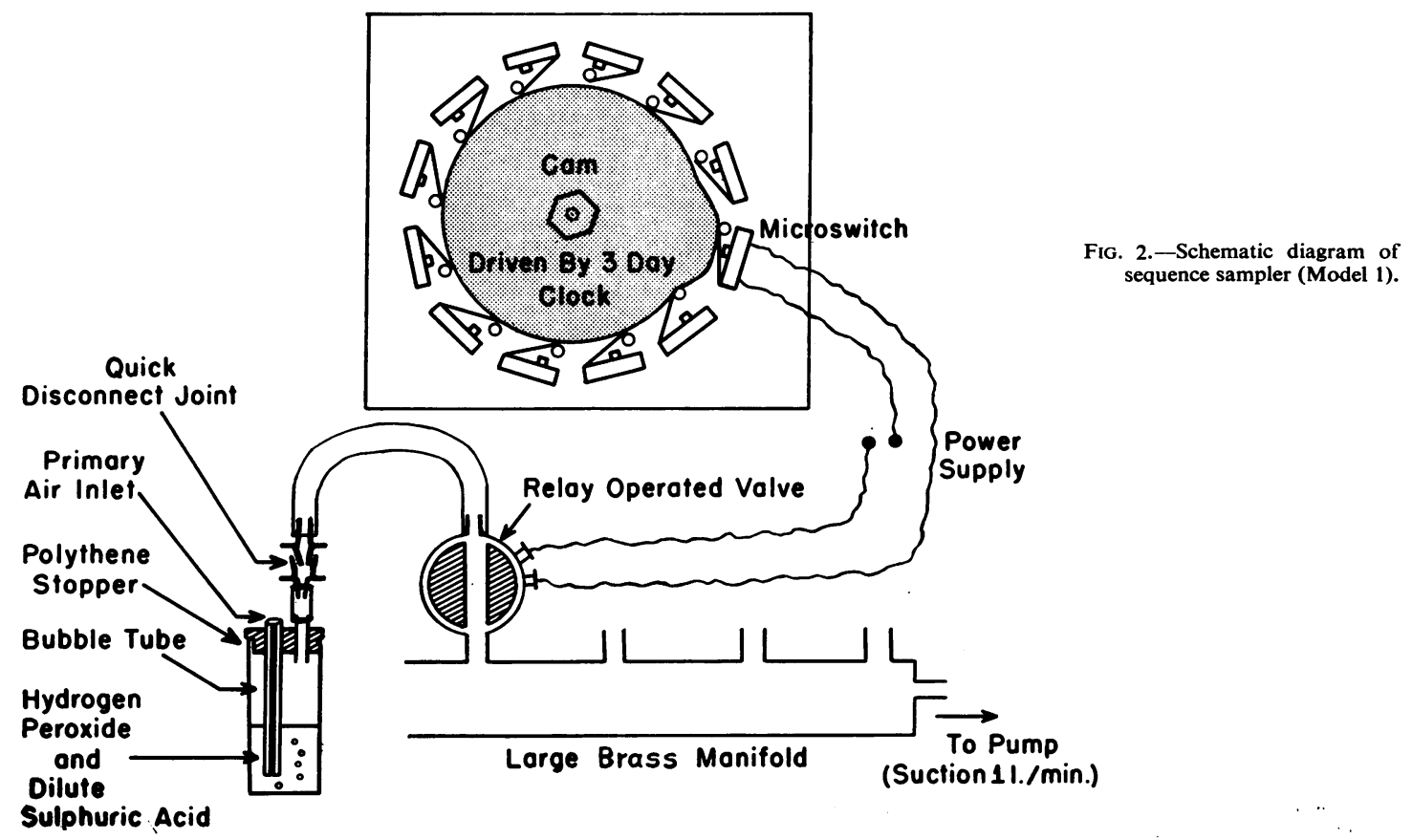




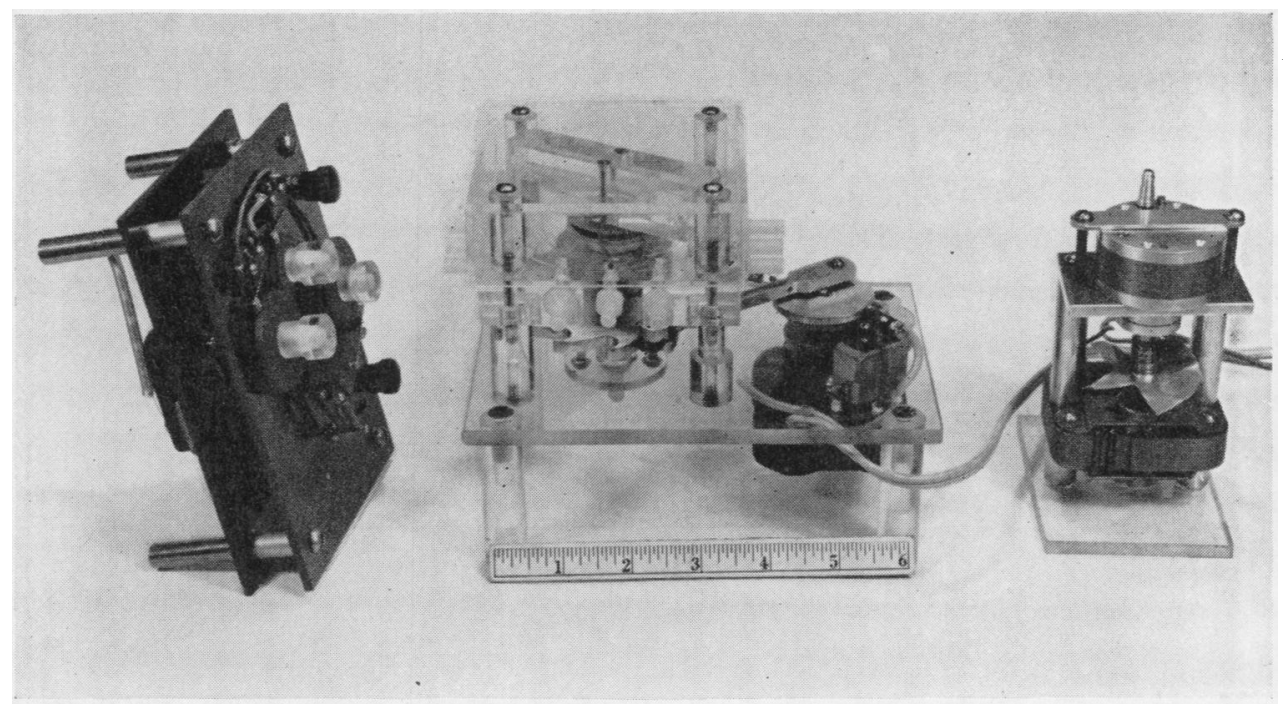

FIG. 3.-General view of modified sequence sampler (Model 2).

T-piece and appropriate capillary "bleeder". This bleeder tube is also essential to provide a by-pass flow of air through the pump during the change-over period when all the solenoid valves would be closed.

Model 2.-In this machine, heat production has been greatly reduced, since the 12 solenoid valves have been replaced by a plastic rotating head through which suction can be applied in sequence to each of the bubbler tubes. The head is moved quickly from one position to the next by a motor and cam mechanism. The timing unit consists of a clock and multiple plastic discs which can be interchanged to give individual sampling times ranging from two min. to six hr. or more. Bubbler tubes of the same type as used in Model 1 are arranged around the selector head. The overall dimensions of the entire unit, including bubbler tubes, are only 17 in. long, 11 in. wide, and 6 in. tall (Fig. 3).

\section{Flow Characteristics of Sampling System}

Some of the factors affecting sampling rate were investigated by operating a series of machines simultaneously for a period of several days. The majority of flow readings were made by rotameter, and it was found that the flow resistance was sufficient to reduce the pump output. In order to calculate the normal output of the pump, it was necessary to construct a pressure-volume curve for each pump and extrapolate to zero resistance (Fig. 4). Comparison of such extrapolated values with flow rates determined directly by low-resistance bellows flowmeter showed good agreement.

Differences in sampling rate attributable to machines, time of testing, bubbler tube (position in rack), and filling of vial ("full" or "low") were evaluated in a formal analysis of variance.

Effects due to Machines.-There is a highly significant component of the total variance attributable to differences between machines. This is largely attributable to varying amounts of dust accumulating in the capillary "bleeder", and will be discussed

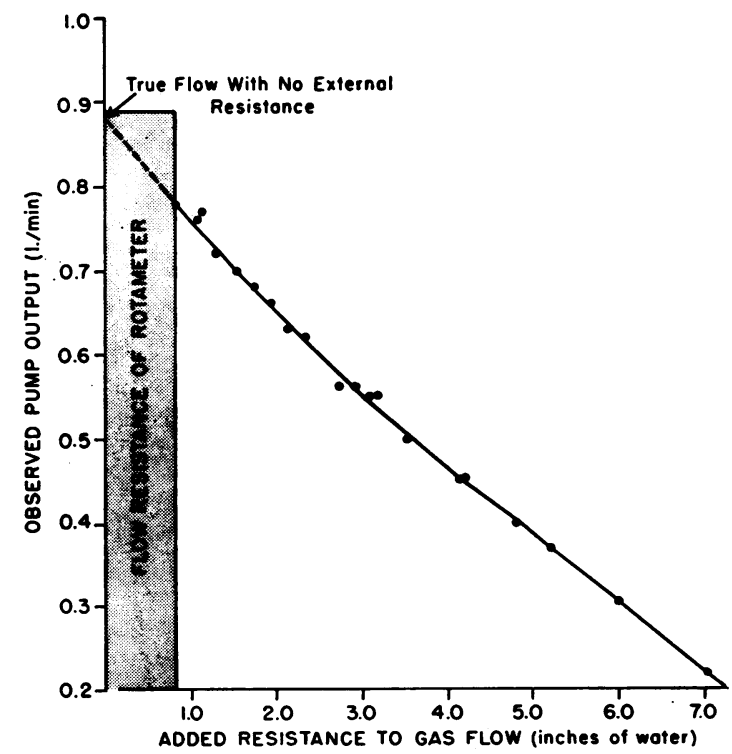

FIG. 4.-Pressure/flow diagram for diaphragm pump used in sequence sampler. 
further in the section on field procedure. After cleaning the "bleeder" with chromic acid, the uniformity of flow in the different machines was restored.

Effects due to Time of Testing.-There are no significant systematic changes of flow when measurements are repeated over the course of a few minutes.

Effect of Position of Tube in Rack.-As might be expected, a small component of the total variance is attributable to the position of the tubes per se, and it is interesting to note also the magnitude of the first order machine/tube interaction. This implies that different bubbler tubes are behaving very differently in the same relative rack position. The critical factors determining flow through an individual vial are as follows:

Length of the Capillary Tube.-Over $90 \%$ of the total flow resistance of the sampling system from the atmosphere to the pump is attributable to the capillary tube. The rate of sampling shows an inverse relationship to the length of the capillary tube:

\begin{tabular}{c|c}
\hline Length (cm.) & Flow (1./min.) \\
\hline 10 & 1.13 \\
20 & 0.77 \\
30 & 0.65 \\
40 & 0.50 \\
50 & 0.33 \\
\hline
\end{tabular}

Variations in Internal Diameter of Capillary Tube.-Commercial capillary tubing has quite a wide nominal latitude with respect to bore, but direct testing of a number of $10 \mathrm{~cm}$. lengths from one batch of $1 \mathrm{~mm}$. tubing revealed variations of not more than $0.04 \mathrm{l} . / \mathrm{min}$. in sampling rate between different tubes.

External Shape of Capillary Tube.-It had been suggested that bubble formation might be facilitated by bevelling the ends of the capillary tubing, but direct measurement with a number of tubes before and after bevelling showed this to be unimportant.

Leakage at Plastic Stoppers. - With repeated use, it was found that some of the stoppers no longer made a perfect gas-tight seal with the glass of the vial. Tubes where leakage exceeded $10 \%$ of the total flow were rejected; since lesser leaks were fairly constant for any given stopper, it was possible to correct for them by determining the flow rate under a standard suction.

Effect of Depth of Filling of Vial.-There is no significant primary component of the flow variance attributable to the depth of filling of the vial, flow rates at the beginning of the sampling period (when the capillary tubes were immersed to a depth of 33 to $35 \mathrm{~mm}$.) being identical with those at the end of the sampling period, when the tubes were immersed to a depth of only 1 to $2 \mathrm{~mm}$. This is probably explained by the relatively small component of the total resistance attributable to passage of a gas bubble through the peroxide solutions. The tube position/filling interaction is highly significant, and is probably due to long-term variations in the power supply which affect all machines similarly over the four- to five-hour period between "full" and "low" flow measurements.

Summarizing this information, the standard error of the flow measurements is $\pm 0.0651 . / \mathrm{min}$., and if three readings are taken over the space of about five minutes, $95 \%$ of observations made in this way will achieve an accuracy of $\pm 0.0751 . / \mathrm{min}$. When the apparatus is used on domestic premises, it is important to minimize the component of variance attributable to "tubes", since only one of the 12 sampling positions can be checked by the visiting nurse. The technique of matching tubes according to flow rate will be described further in the section on field procedure.

\section{Evaporation of Absorbent Solution}

Perhaps the most serious problem with the original apparatus is that over the six-hour sampling period, the volume of peroxide solution is greatly reduced by evaporation, often to one-third of the original volume. Theoretical considerations suggest that at least four factors affect evaporation:

Water Vapour Content of Room Air.-At normal room temperatures $\left(65-75^{\circ} \mathrm{F}\right.$.), fluctuations of relative humidity can produce appreciable changes in the water vapour content of the atmosphere. Expressing this in terms of partial pressure, extreme values of 3.3 and $12.6 \mathrm{~mm}$. $\mathrm{Hg}$ were observed over a threemonth period.

Volume of Air Drawn through Sampling Vials.The importance of the flow rate in determining evaporation is evident from Table 1.

Temperature of Sampling Vials.-Enclosure of the entire apparatus within a sound-proof box creates a considerable heat dispersion problem. Some of the heat is generated by the pump and the telechron motor, but a more important source is probably the solenoids, since they are close to the sampling vials. The temperature of the peroxide solution is often as much as $30^{\circ} \mathrm{F}$. above room temperature.

The importance of an increase of temperature in promoting evaporation is illustrated by a simple experiment in which an apparatus was removed from its cabinet. Initially, the temperature of the peroxide was little above that of the room, but as 
TABLE 1

RELATIONSHIP BETWEEN EVAPORATION AND FLOW THROUGH SAMPLING UNIT

\begin{tabular}{|c|c|c|c|c|c|c|c|c|}
\hline Machine No. & 1 & 2 & 3 & 4 & 5 & 6 & 7 & 8 \\
\hline $\begin{array}{l}\text { Average evaporation (ml.) } \\
\text { Average flow (1./min.) } \\
\text { Evaporation: fow ratio }\end{array}$ & $\begin{array}{l}13 \cdot 2 \\
1.65 \\
8 \cdot 0\end{array}$ & $\begin{array}{l}9 \cdot 7 \\
1 \cdot 20 \\
8 \cdot 1\end{array}$ & $\begin{array}{l}7 \cdot 0 \\
0 \cdot 84 \\
8 \cdot 3\end{array}$ & $\begin{array}{l}10 \cdot 0 \\
1 \cdot 12 \\
8 \cdot 9\end{array}$ & $\begin{array}{l}9 \cdot 6 \\
1.02 \\
9 \cdot 4\end{array}$ & $\begin{array}{l}9 \cdot 4 \\
1 \cdot 41 \\
6 \cdot 7\end{array}$ & $\begin{array}{l}11 \cdot 4 \\
1 \cdot 24 \\
9 \cdot 2\end{array}$ & $\begin{array}{l}5 \cdot 6 \\
1 \cdot 13 \\
4 \cdot 9\end{array}$ \\
\hline
\end{tabular}

TABLE 2

RELATIONSHIP BETWEEN TEMPERATURE OF SAMPLING TUBE AND AMOUNT OF EVAPORATION

\begin{tabular}{|c|c|c|c|c|c|}
\hline $\begin{array}{c}\text { Temperature } \\
\text { of Sample } \\
\left({ }^{\circ} \mathbf{F} .\right)\end{array}$ & $\begin{array}{c}\text { Temperature } \\
\text { of Room } \\
\left({ }^{\circ} \mathrm{F} .\right)\end{array}$ & $\begin{array}{c}\text { Relative } \\
\text { Humidity } \\
(\%)\end{array}$ & $\begin{array}{c}\text { Flow } \\
(1 . / \mathrm{min} .)\end{array}$ & $\begin{array}{c}\text { Sampling } \\
\text { Time } \\
\text { (hr.) }\end{array}$ & $\begin{array}{l}\text { Evaporation } \\
\text { (ml.) }\end{array}$ \\
\hline $\begin{array}{r}82 \\
88 \\
135\end{array}$ & $\begin{array}{l}70 \\
70 \\
70\end{array}$ & $\begin{array}{l}40 \\
52 \\
40\end{array}$ & $\begin{array}{l}1.0 \\
1.0 \\
1.0\end{array}$ & $\begin{array}{l}2 \\
2 \\
2\end{array}$ & $\begin{array}{l}1 \cdot 7 \\
3 \cdot 0 \\
7 \cdot 7\end{array}$ \\
\hline
\end{tabular}

the apparatus was brought closer to a radiator, evaporation was markedly increased (Table 2).

It is difficult to obtain true average temperatures for the different cabinets, since the heat production varies from solenoid to solenoid, and even with any one solenoid from time to time. However, the lowest cabinet temperature observed was $14^{\circ} \mathrm{F}$. above room temperature, and the highest $40^{\circ} \mathrm{F}$. above room temperature.

Degree of Saturation with Water Vapour.Theoretical considerations suggest that the air stream reaches $80-90 \%$ saturation at the temperature of the sampling solution. Consider a cabinet in a room at $70^{\circ} \mathrm{F}$., and $33 \%$ relative humidity, the temperature inside the cabinet being $88^{\circ} \mathrm{F}$. Room air contains water vapour equivalent to a partial pressure of $6.6 \mathrm{~mm}$. $\mathrm{Hg}$, while the vapour pressure with full saturation at $88^{\circ} \mathrm{F}$. is $33.9 \mathrm{~mm}$. $\mathrm{Hg}$. The air will therefore require $27 \cdot 3 / 760$ litres of water vapour per litre to achieve full saturation. For one such cabinet, the total gas flow over a six-hour period was 409 litres, giving an uptake of $10.6 \mathrm{ml}$. of liquid for full saturation at $88^{\circ} \mathrm{F}$. Direct measurement showed an average loss of $9.4 \mathrm{ml}$, indicating approximately $89 \%$ saturation.

An alternative approach is to operate a four-stage sampler at a comparable flow rate, and note the fluid loss in successive stages. Ten experiments of this type showed a total uptake for the four tubes that was invariably greater than the amount required to produce full saturation. This could not be explained in terms of spray being carried into the gas stream, and seemed due to a small amount of dry air leaking into the system around the stopper of each sampling vial. Assuming water loss at the fourth stage to be due entirely to this cause, it is possible to calculate corrected values for evaporation at the other three stages. At the first stage, the average value is $84.7 \%$, agreeing well with the estimate made on theoretical grounds.
There are two possible methods of reducing evaporation. One is to increase the humidity of the air in the cabinet by feeding a continuous drip of water onto a suitable evaporating surface. This was rejected since a proportion of the gaseous acid might dissolve in the evaporating fluid, and oxidation of sulphur dioxide to the less readily absorbed sulphur trioxide would be promoted by the increased humidity. A more satisfactory approach is to decrease local heating by installing the solenoids, motor, and pump in an asbestos container ventilated independently of the rest of the cabinet. Modification of the sampling units along these lines has reduced evaporation from an average of $60 \%$ of the initial volume to 20 to $30 \%$.

\section{Calibration of Conductivity Apparatus}

The specific resistance of the samples is measured by a standard conductivity bridge (Industrial Instruments, Inc., Cedar Grove, N.J.), the bubbler tubes being maintained at $80^{\circ} \mathrm{F}$. by immersion in a constant-temperature bath. The apparatus was calibrated initially against sulphuric acid solutions of known normality prepared gravimetrically (Fig. 5). Over the range of interest in air-pollution work (specific resistance $10,000-50,000$ ohms.), it is possible to read the bridge to the nearest 500 ohms. (rather more accurately at the lower resistance levels), giving an error of up to $5 \%$ in the estimate of sulphuric acid concentration. The readings are also quite sensitive to temperature, but once the bubbler tubes have warmed to the temperature of the waterbath, there is no further change of conductivity until the volume of solution is altered by evaporation.

Having determined the concentration of sulphuric acid in mg. per $15 \mathrm{ml}$. sample, it is necessary to convert the reading to parts per million of $\mathrm{SO}_{2}$ in the atmosphere. At the temperature commonly found in the homes of our patients $\left(25^{\circ} \mathrm{C}\right.$. $), 1 \mathrm{mg}$. of liquid sulphuric acid is equivalent to $0.250 \mathrm{ml}$. of 


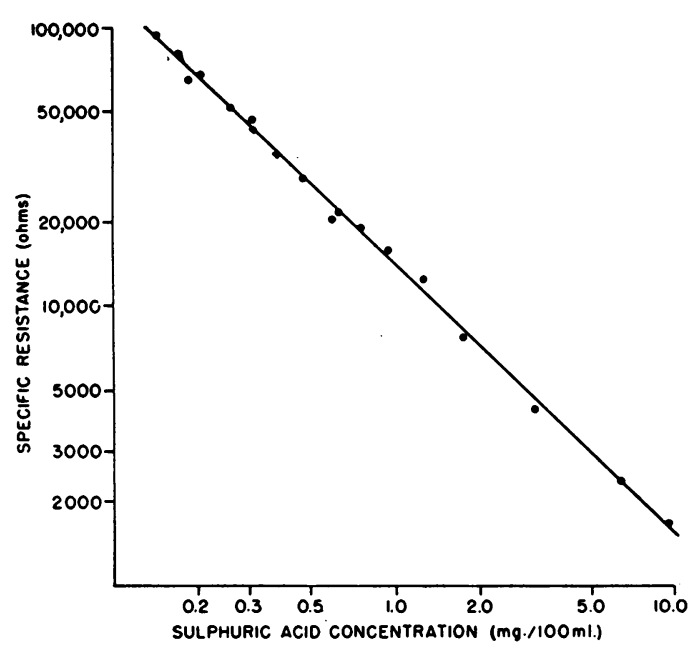

FIG. 5.-Calibration curve for conductivity bridge.

sulphuric acid or $\mathrm{SO}_{2}$ in the vapour phase. Since the acid absorbed by the peroxide solution has been obtained from xt litres of room air ( $x$ being the bubbler flow in 1./min., and the total sampling time), an acid content of $\mathrm{y} \mathrm{mg}$. will be equivalent to $250 \mathrm{y} / \mathrm{xt}$ p.p.m. of gaseous acid in the environment.

It will be noted that accurate timing of the solenoids is as important as the accurate measurement of conductivity in this calculation. This involves accurate positioning of the micro-switches in relation to the cam. The task could be made easier in future models by fixing the micro-switches in sliding grooves, or fitting switches with contacts of adjustable length. In practice, it is advisable to allow a short period in each six-hour cycle when all valves are closed in order to give the nurse adequate opportunity to change the bubbler tubes. This blank period must be timed accurately, and allowance made for it in the final calculations.

\section{Efficiency of Single-stage Sampling}

Theoretical considerations suggest that the efficiency of uptake of gaseous acid will be influenced by a variety of factors, including: (1) The shape and size of the gas bubbles; (2) the average contact time between gaseous and aqueous phases; (3) the temperature of the two phases.

Only the overall efficiency is of practical importance; this has been estimated by a four-stage sampling technique. The average value for 11 experiments was $95.3 \%$, and in only two of the 11 experiments was the efficiency less than $90 \%$. This compares well with more elaborate types of apparatus (Wilson, 1954; Lombardo, 1953). In two experiments where sampling was continued for 18 hours, evaporation was such that the capillary tube at the first stage was no longer in contact with the peroxide solution; in these experiments the efficiency dropped to 73 and $80 \%$ respectively.

In the early stages of this work, it was thought that the distance between the bubbler tube and the impingement plate would need to be rigidly controlled, and miniature plates of the Wilson (1954) type were made. However, direct comparison of such units with the simpler bubbler tubes in a fume chamber containing high concentrations of sulphur dioxide (2-20 p.p.m.) showed that there was no significant difference between the three systems, each showing a collecting efficiency of 93 to $95 \%$.

\section{Field Procedure}

Where a considerable number of sampling units are operated simultaneously in different parts of a city, as during the recent air pollution survey, certain standard procedures become necessary. Each home is allocated two racks of numbered bubbler tubes, carefully matched for flow characteristics in order that the same factors may be used in subsequent calculations. The visiting nurse or technician reaches the home a little before the time of operation of the solenoid valve, and at the moment the valve closes, the quick disconnect joints are undone, and the new rack of bubbler tubes installed. The number of the last bubbler tube in the old rack and the first tube in the new rack are recorded on a suitable data sheet, and the old rack is brought back to the laboratory for measurement of electrical conductivity.

At this time, bubbler tubes are also checked for leakage by measuring the flow rate against standard suction. This is of some importance since, during a field visit, it is only possible to check flow through one of the 12 tubes.

Field checking of sampling rates is by means of a small rotameter (Brooks Rotameter Company) carefully calibrated in the laboratory. A small but progressive increase of gas flow rates was noted over the course of three months' operation. This was traced to a gradual accumulation of dirt in the capillary "bleeder". If it were desired to maintain an absolutely constant rate of sampling (as opposed to frequent rotameter checks), it would be necessary to have two matched "bleeder" tubes, and clean each weekly by immersion in chromic acid.

\section{Significance of Measurements}

It has been pointed out by Thomas, Ivie, and Fitt (1946) that the conductivity method is affected by gaseous contaminants other than the oxides of sulphur, notably hydrogen chloride and ammonia. The levels of these last two contaminants in the atmosphere of Cincinnati were investigated over a five-year period by Cholak, Schafer, and Hoffer (1952). Interpretation of the data is complicated by the fact that only "spot" samples were obtained and no samples were collected during wet weather, but 
there is sufficient evidence to suggest that the concentrations of ammonia and chlorides are approximately equal, so that their effect on $p \mathrm{H}$ and hence on electrical conductivity should be slight. Neither amounts to more than $50 \%$ of the observed sulphur dioxide levels (measured as total sulphate).

Although some authors (Fox and Groves, 1932) have assumed that a simpler bubbler absorbs all of the "sulphur acids", critical investigation has shown that the amount of sulphur trioxide and sulphuric acid mist retained is slight unless very fine bubbles are produced by a sintered glass unit (Johnstone, 1931; Gillham, 1946) and the contact time is prolonged (Greenwood, 1939). However, the amount of sulphuric acid mist in the air of Cincinnati, even on a winter day, is small. Direct measurement of this contaminant was made by a modification of the method of Coste and Courtier (1936). Four sampling vials were arranged in series. The first two contained the standard peroxide absorbent, the third acted as a trap (it remained completely dry throughout the test), while the fourth was surrounded by ice to allow condensation of moisture, and the trapping of any aerosols. Over a period of 16 hours, some $15 \mathrm{ml}$. of condensate was obtained and measurement of electrical conductivity showed an acid content that was a little more than $3 \%$ of the value recorded for the peroxide solution. This agrees well with estimates made in other cities in the United States (Amdur, Schulz, and Drinker, 1952; Mader, Hamming, and Bellin, 1950). The fact that the sulphur trioxide level is so low implies that little would be gained by redesigning the bubbler unit to give complete absorption; variations in conductivity due to $\mathrm{SO}_{3}$ would be submerged.

It must be concluded that except in areas where the level of atmospheric sulphur dioxide is unusually high, the measurement of "gaseous acid" is a relatively non-specific index of air pollution. However, as will appear in a following section, it is capable of yielding information that differs significantly from that given by other non-specific indices of pollution such as the determination of suspended particulate matter.

\section{Variation between Sampling Units}

In the Same Room.- - It has already been noted that concentrations of gaseous acid can vary widely over comparatively short distances, and this immediately raises the question of the significance of measurements made at any one point in a room.

To investigate this problem, eight machines were distributed about a fairly large laboratory. In the first experiment, the $\mathrm{SO}_{3}$ content of the air was artificially increased by placing several dishes of fuming sulphuric acid in front of an electric fan. An analysis of variance for three days' operation under these conditions showed that there was an almost one hundredfold gradient of gaseous acid across the breadth of the room. This was rather surprising, since a series of Hemeon smoke samplers, operating concurrently, showed a maximum difference of $25 \%$ in the suspended particulate matter at different points in the room. A possible explanation is that in the immediate vicinity of the evaporating dishes the $\mathrm{SO}_{3}$ is in gaseous form, which is readily absorbed in the sampling vials, but as the fume crosses the room it is rapidly hydrated to sulphuric acid aerosol which is not absorbed.

Repetition of the experiment without the forced draught of $\mathrm{SO}_{3}$ gave values that were reasonably similar at different points in the room. The total observational variance was such that any six-hour measurement made with one machine at one point in a room had $95 \%$ confidence limits of $\pm 28 \times 10^{-4}$ p.p.m. $\mathrm{SO}_{2}$. This is at least adequate for estimating the mean daily gaseous acid levels in a room, and compares quite well with values for the Wilson sequence sampler operated under similar conditions $(95 \%$ confidence limits for one-hour sample \pm $45 \times 10^{-4}$ p.p.m. $\mathrm{SO}_{2}$ ).

Readings Inside and Outside of a Building.-The penetration of gaseous acid into a closed room was followed for a two-month period. Two-hourly Wilson sequence samplers were operated inside and outside a room in the Cincinnati General Hospital. The room was the size of a typical bedroom, and the windows and door were closed except when the samples were being changed. Linear regression methods were utilized in measuring the extent of the relationship between inside and outside measurements. Table 3 shows the percentage of the variation of inside measurements attributable to variations in external gaseous acid for different lag periods. It will be noted that there is a maximum correspondence with a lag of somewhere between zero and two hours, the exact value being perhaps somewhat closer to two hours. The inside values did not show the same sharp peaks as the outside values, and the

TABLE 3

PERCENTAGE VARIATION COMMON TO INTERNAL AND EXTERNAL LEVELS OF GASEOUS ACID FOR VARIOUS EXTER NAL DISCREPANCIES IN TIME OF SAMPLING

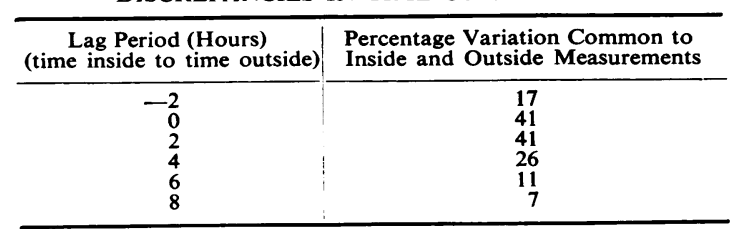


TABLE 4

PROPORTION OF GASEOUS ACID PENETRATING CLOSED ROOM AT DIFFERING EXTERNAL CONCENTRATIONS

\begin{tabular}{c|c|c}
\hline $\begin{array}{c}\text { External } \\
\text { Concentration } \\
\text { (p.p.m.) }\end{array}$ & $\begin{array}{c}\text { Internal } \\
\text { Concentration } \\
\text { (p.p.m.) }\end{array}$ & $\begin{array}{c}\text { Inside/Outside } \\
\text { (\%) }\end{array}$ \\
\hline 0.08 & 0.060 & 75 \\
0.16 & 0.095 & 59 \\
0.24 & 0.120 & 50 \\
0.32 & 0.140 & 44 \\
0.40 & 0.160 & 40 \\
0.48 & 0.175 & 36 \\
\hline
\end{tabular}

mean indoor value was no more than $64 \%$ of the outside value over the entire two-month period. It is also interesting to note (Table 4) that with increasing external concentrations of gaseous acid, the proportion penetrating the building materially decreased. This may be because many of the peaks of contamination were of comparatively short duration.

As a consequence of the average lag of almost two hours, it follows that when the outside concentration is falling rapidly, the inside value may exceed the outside value for a time and this has actually been observed on a number of occasions. The smaller variation of gaseous acid in the home is of some practical importance in that it suggests that reliable information can be obtained with a lower frequency of sampling than is necessary out of doors.

Variation between Different Outdoor Stations.Hourly samples were obtained from each of three outdoor stations in different parts of the town over the course of a three-month period. Highest values were consistently recorded from a downtown area (city parking lot); taking this as unity, values at the two suburban locations (medical school two miles north of the city centre and Abbé Observatory four miles north of city centre) showed a slight decrease as winter developed. Relative monthly levels of gaseous acid, taking the city parking lot as unity, were as follows:

\begin{tabular}{l|c|c|c}
\hline & October & November & December \\
\cline { 2 - 3 } City parking lot & 1.00 & 1.00 & 1.00 \\
Abbé Observatory & 0.56 & 0.45 & 0.43 \\
\hline
\end{tabular}

This change is probably related to the greater density of housing units in the downtown area. Thus, a higher proportion of the downtown gaseous acid is attributable to the domestic heating load and there is a correspondingly greater seasonal variation in contaminants from this source. Since the relationship between outdoor stations is by no means constant, it is necessary to operate a fair number of sampling units simultaneously to obtain an overall picture of the pollution of a city at any given time.
Relations to Other Indices of Atmospheric Pollution

A number of authors have noted a relationship between gaseous acid levels and the concentration of suspended particulate matter, and it may be asked whether any advantage is derived from measuring both quantities. However, simple graphical examination of the data (Fig. 6) is sufficient to show that the relationship between the two indices of pollution varies considerably from one part of the city to another. In the downtown area (city parking lot) (Fig. 6a) the gaseous acid follows the pattern of particulate concentrations fairly closely, although there is apparently a lag of two to three hours between the two curves. The ratio of the two measurements is also fairly constant under conditions of high and low pollution averaging 40 to $60 \mathrm{COH}^{*}$ units per p.p.m. At the Abbé Observatory (Fig. 6b), situated on a high bluff overlooking an industrial valley, there is little or no lag between the two curves, but the gaseous acid levels are not sustained for as long as the smoke readings. It may be that there is more free ammonia in this area giving rapid neutralization of the gaseous acid; this would also explain why under conditions of low pollution the particulate levels bear a very high ratio to gaseous acid concentrations ( 2 to 300 $\mathrm{COH}$ units per p.p.m.). The third station (medical school) occupies a geographic position intermediate between that of the Abbé Observatory and the city parking lot. Here, the gaseous acid curve lags behind the particulate curve by 0 to 1 hour, and the acid level is maintained for a similar period to the particulate matter.

RATIO OF PARTICULATE MATTER TO GASEOUS ACID AT THREE LOCATIONS

\begin{tabular}{l|c|c|c}
\hline & $\begin{array}{c}\text { Abbé } \\
\text { Observatory }\end{array}$ & $\begin{array}{c}\text { Medical } \\
\text { School }\end{array}$ & $\begin{array}{c}\text { City } \\
\text { Parking Lot }\end{array}$ \\
\cline { 2 - 3 } Light pollution & 213 & 369 & 77 \\
Heavy pollution & 69 & 82 & 47 \\
\hline
\end{tabular}

\section{Other Possible Applications}

Although designed primarily for use in a domestic air hygiene survey, the compact portable nature of this apparatus suggests that it may find ready application in many industrial situations where accurate sequential measurements of gaseous contaminants are desired. The low cost and simplicity of operation also make the apparatus very suitable for large-scale grid measurements of gaseous acids in a large city.

* A COH unit may be defined as that quantity of suspended particulate matter which, when deposited on a filter strip, produces on optical density of 0.01 . 


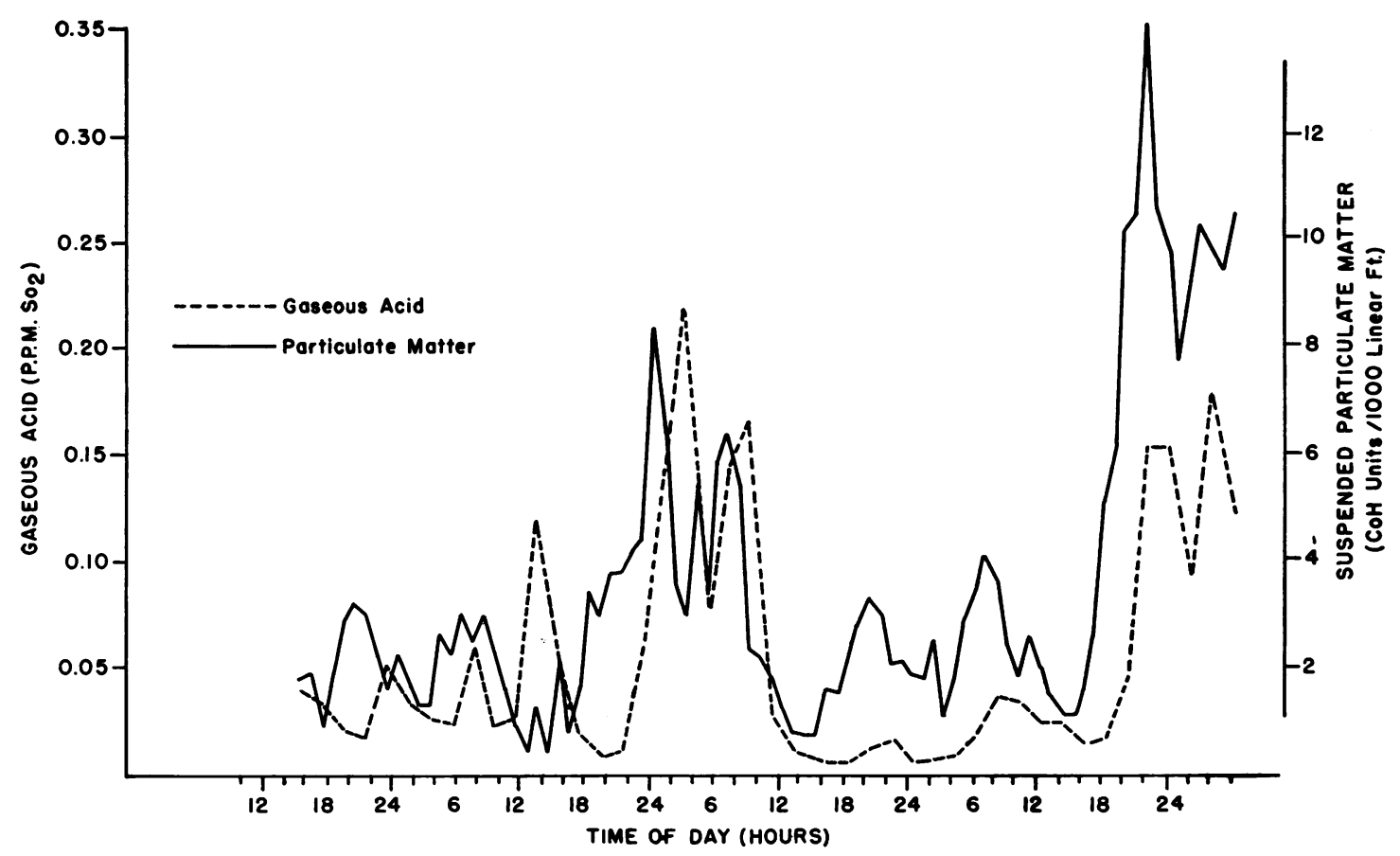

(a)

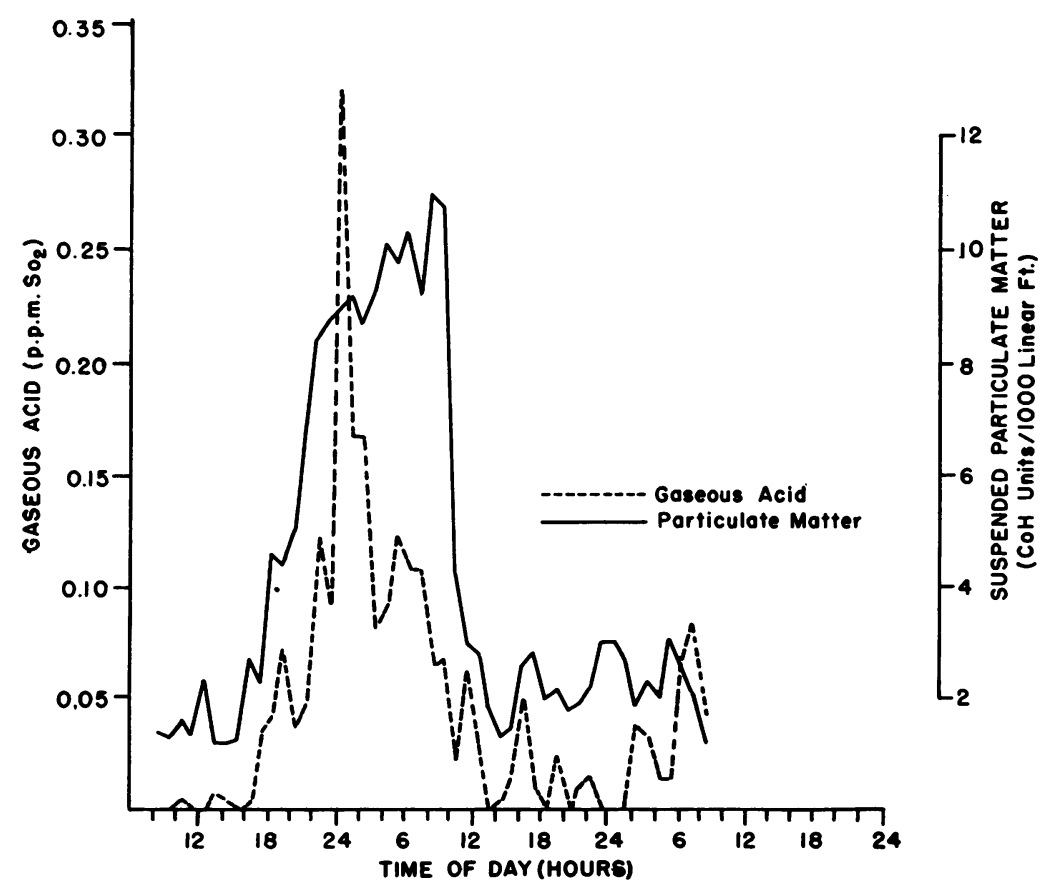

FIG. 6.-Relationship between gaseous acid and suspended particulate matter.

(a) At downtown location

(b) At the Abbé Observatory

(b) 


\section{Summary}

A description is given of a small sequence sampler that gives six-hourly readings of gaseous acid concentration in domestic premises. Samples are returned to the laboratory for analysis by the conductivity method. Factors affecting the rate of sampling and evaporation of absorbent solution are critically evaluated. Evaporation is an important problem with the original model and methods of minimizing water loss have been incorporated in later designs of the apparatus. Gaseous acid measurements largely reflect the amount of $\mathrm{SO}_{2}$ in a suburban atmosphere and an efficiency of $95 \%$ can be obtained with single-stage sampling. Ammonia and hydrochloric acid vapour are also absorbed although these are present in lesser and approximately equal amounts. Sulphur trioxide is not absorbed to any significant extent, but this is a minor constituent of suburban atmospheres.

The variation between different sampling units in the same room is considerable in the presence of dry gaseous $\mathrm{SO}_{3}$, and even under normal room conditions the $95 \%$ confidence limits of observations made from a single point are \pm 0.0024 p.p.m. Differences between different parts of a large building are even greater. Indoor measurements show a general tendency to follow outdoor readings with a lag of up to two hours; however, the indoor concentrations of gaseous acid are on the average much lower, and do not show the sharp peaks seen at outside locations. The relationship between gaseous acid levels in different parts of the city is not constant since in each area the industrial output is supplemented by a seasonally varying domestic heating load. The relationship between gaseous acid and particulate contaminants also varies in different parts of the town, perhaps on account of differing amounts of alkaline pollutants in the atmosphere.

\section{REFERENCES}

Amdur, M. O., Schulz, R.Z., and Drinker, P. (1952). A.M.A. Arch. industr. Hyg., $5,318$.

Carey, G. C. R., Phair, J. J., Shephard, R. J., Thomson, M. L., and Turner. M. E. The 1956 Air Hygiene Survey in the City of Cincinnati. In preparation.

Cholak, J., Schafer, L. J., and Hoffer, R. H. (1952). A.M.A. Arch. industr. Hyg., 6, 314.

Coste, J. H., and Courtier, G. B. (1936). Trans, Farad. Soc., 32, 1198.

Fox, J. J., and Groves, L.G. (1932). J. Soc. chem. Ind. (Lond.), 51, 7T

Giever, P. M. (1952). A.M.A. Arch. industr. Hyg., 6, 445.

Gillham, E. W. F. (1946). J. Soc. chem. Ind. (Lond.), 65, 370.

Gillham, E. W. F. (1946). J. Soc. chem. Ind. (Lond.),

Greenwood, H. D. (1939). Industr. Chemist, 15, 113.

Johnstone, H. F. (1931). Industr. Engng Chem. 23
Lombardo, J. B. (1953). Analyt. Chem., 25, 154.

Lombardo, J. B. (1953). Analyt. Chem., 25, 154 .
Mader, P. P., Hamming, W. J., and Bellin, A. (1950). Ibid., 22, 1181 .
Ministry of Health (1954). Reports on Public Health and Medical Subjects. No. 95: Mortality and Morbidity during the London Fog of December, 1952. H.M. Stationery Office, London.

Saillard, E., and Bregmann (1917). Rev. gén. Chim., 20, 69.

Setterstrom, C., and Zimmermann, P. W. (1938). Contrib. Boyce Thompson Inst., 9, 171 .

Singh, A. D. (1939). 'A Survey of Sulphur Dioxide Pollution in Chicago and Vicinity. University of Illinois. Engineering Experiment Station. Circular No. 36.

Thomas, M. D. (1932). Industr. Engng Chem. (Anal. Ed.), 4, 253.

, and Abersold, J. H. (1929). Ibid., 1, 14. $18,383$.

Wilson, W. L. (1954). An Automatic Impinger for Air Sampling. Annual Meeting, Air Pollution Control Association. Chattanooga, Tennessee, May 3-6, 1954. 